\title{
Can Morningstar Analyst Ratings Predict Fund Performance?
}

\author{
Rashiqa Kamal, University of Wisconsin-Whitewater, USA
}

\begin{abstract}
This paper analyzes the Morningstar Inc.'s new Analyst Ratings that were introduced in November 2011. The ratings are intended to help investors make long-term investment decisions. According to Morningstar, these ratings reflect the long-term risk-adjusted performance of mutual funds. This paper examines whether the Analyst Ratings can predict future fund performance. We assume that the rated funds would have a similar rating in 2010, since they are not based on short-term performance measures, and using quantile regressions, we find that the Analyst Ratings are significantly positively related to future fund performance, measured by Alpha in 2012, that captures the performance over the past three years, 2010, 2011, and 2012. The Analyst Rating is a synthesis of five individual aspects (pillars) of a fund, namely, People, Parent, Process, Performance, and Price. We also find that funds with a higher People Rating will perform better in the future. Since Morningstar contends that the Analyst Ratings are not based on short-term measures of performance, we test this statement also, and using Ordinary Least Squares model find that these ratings are in fact, significantly positively related to contemporaneous fund performance, using the Sharpe Ratio, as a measure. In spite of the assumptions made in this analysis, we argue that these results are important as this paper is the first to analyze the Analyst Ratings and we present some important findings.
\end{abstract}

Keywords: Morningstar Analyst Rating; Pillar Ratings; Fund Performance; Sharpe Ratio

\section{INTRODUCTION}

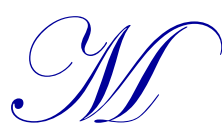

orningstar Inc. is an independent investment research provider that provides data and research on various investment vehicles including mutual funds. Morningstar provides different types of ratings to the mutual funds in an attempt to assist the investors in making informed choices. The most well-known performance Star Ratings of mutual funds assigned by Morningstar are considered a valuable and unbiased source of information by individual and institutional investors. Del Guercio and Tkac (2008) present evidence on the popularity and credibility of the Morningstar Star Rating system, among the investors (pp. 911). According to Morningstar Fact Sheet (2013), the star ratings for mutual funds first debuted in 1985. According to Haslem (2013), "The Morningstar Rating is a quantitative measure of mutual fund past performance that includes both risk and return elements and ranks funds from one to five stars." In 2004, Morningstar debuted the Stewardship Grades for mutual funds that grade mutual funds on set attributes, namely, regulatory issues, board quality, manager incentives, fees, and corporate culture, in an attempt to evaluate the governance practices of mutual funds. The information for grading the mutual funds on these attributes is obtained from public filings and survey responses. Unlike the Morningstar Star Ratings, these grades are based on some quantitative, but mostly qualitative information. The Stewardship Grade is the sum of the assigned grade points to each of the above attributes, and ranges from 'A' to 'F'. In 2007, Morningstar revised the methodology for calculating the Stewardship Grades by changing the underlying criteria for evaluation of some of the fund attributes. Morningstar Analyst Ratings were introduced in November 2011, in an attempt to rate mutual funds based on their long-term potential for superior risk-adjusted performance. The overall rating is based on five pillars: People, Process, Parent, Performance, and Price. Morningstar considers these fundamental areas to be vital to the funds' long-term success (Kinnel, 2011).

The popularity of Morningstar's various ratings and grades has inspired a plethora of academic literature. Studies have been conducted to evaluate whether a particular rating or grade affects the performance of the funds, or 
whether a change in the ratings affects the funds in any way. Blake and Morey (2000) study whether the Morningstar Rating System can predict the performance of domestic U.S. equity funds and find that lower ratings from Morningstar generally indicate relatively poor future performance. Morey (2005) finds that 3 years after receiving a 5-star Morningstar rating, fund performance severely falls off and the risk levels of the funds rise for a sample of funds between July 1993 and July 2001. Del Guercio and Tkac (2008) find that for upgraded ratings, fund inflows increase significantly, and fall significantly for rating downgrades over the period of November 1996 and October 1999. Stewardship Grades have also attracted their share of academic research. Most notably, Wellman and Zhou (2007) examine the first release of the Morningstar Stewardship Grades on August 24, 2004, and find that funds receiving good grades outperformed funds with bad grades over the period January 2001 to December 2006. They also present evidence that investors sold funds with poor grades and bought funds with good grades after the announcement day. Recently, Chen and Huang (2011) study the relation between mutual fund performance and Stewardship Grade using quantile regression models, and find a strong contemporaneous association between Stewardship Grade and fund performance. They also find that board quality, one of the fund attributes for determining Stewardship Grade is strongly related to funds' future performance. To our knowledge, there is no academic study on the more recent Morningstar Analyst Ratings. In this paper, we examine whether Morningstar Analyst Ratings can predict future fund performance, and whether they are related to contemporaneous fund performance.

Using quantile regression methods, we find that the Analyst Ratings significantly predict future performance, as measured by the 3-year Alpha. The results also indicate that the People pillar of these ratings has a significant predictive power for funds' future performance. Our results are based on certain assumptions, which are necessary because as mentioned above, Analyst Ratings were introduced in November 2011, so there is not enough data to support our conjectures and tests. Our first assumption is that all the funds in our dataset were rated in December 2012. Since according to Morningstar, these ratings are meant to be an indicator of long-term performance and are not influenced by short-term performance measures, we assume that the ratings will not be changed frequently, and so even if a fund was rated in November 2011 or in early 2012 or early 2013, its rating should be consistent in December 2012. Another reason for this assumption is that our main source of data is Morningstar Direct and it does not report the date of the rating. Based on the same argument, to examine whether the Analyst Ratings can predict future performance, we assume that the funds would have the same Analyst Rating two years ago that they have in 2012. However, even though, we know that the Analyst Ratings are unrelated to the Morningstar Star Ratings, to be consistent, for these tests, we only use the funds that have a consistent Star Rating over these two years. Although the results in this paper are sensitive to the above-mentioned assumptions, we believe that they make an important contribution because investors depend a lot on the Morningstar Ratings and since, the Analyst Ratings are meant to guide investors regarding long-term fund performance, they will be useful for investors and practitioners. As more data becomes available, the tests in this paper can be re-done and results can be updated. Nevertheless, for now it does appear that the Analyst Ratings do have the predictive power for future fund performance and so investors looking for good future fund performance should pay attention to high Analyst Ratings, along with high People ratings. We also find that even though Morningstar states that these ratings are not based on current or past performance, there is a strong contemporaneous relation between the Analyst Ratings and fund performance, as measured by the Sharpe Ratio in 2012.

The rest of the paper is organized as follows: section 2 describes Morningstar's methodology for assigning the Analyst Ratings, and develops the hypotheses. Section 3 talks about the sample and methodology of the paper. Results are presented in section 4 and section 5 concludes.

\section{MORNINGSTAR ANALYST RATINGS}

\subsection{Methodology for the Ratings}

Kinnel (2011) discusses at length the process of assigning the new Analyst Ratings. According to Kinnel (2011), these new ratings will replace the "Picks" and "Pans" that Morningstar has been using since 1999 to indicate the best and worst funds. Like the "Picks" and "Pans", Morningstar rates the funds based on their long-term potential for superior risk-adjusted performance. There are three separate ratings committees based on asset class, which are comprised of top analysts of Morningstar. To analyze the fundamentals of a fund, these analysts break 
them down into five pillars, namely, People, Process, Parent, Performance, and Price. Each of the pillars is rated as Positive, Negative, or Neutral. Kinnel (2011) points out that the overall Analyst Rating is not the simple tally of each of these pillars, in fact, each of these pillars are analyzed independently; however, they do have some overlap, which varies from fund to fund. A synthesis of the five pillars results in five levels of ratings; namely, Gold, Silver, Bronze, Neutral, and Negative. Below, we summarize each of the pillars briefly. Please see Kinnel (2011) for more details.

First, the People pillar is based on the premise that besides the manager, there are other individuals associated with a fund whose expertise, experience and demonstrated skills also affect the fund's performance. This pillar takes into account all of these individuals through manager interviews, site visits, public filings, media interviews and the like. A low People pillar rating does not necessarily point to a poor manager, but might indicate insufficient demonstration of expertise or experience in the particular area, or insufficient track record. Second, Process pillar analyzes the fund strategies, and fund specific competitive advantages, in terms of available resources and manager expertise. Third, Parent pillar looks at the stability and experience of the company running the fund. Some of the factors analyzed under this pillar include investment culture, quality of research, ethics, directors, SEC sanctions, and short-term profits versus shareholder long-term interests. Fourth, Performance pillar focuses on the current and long-term manager performance, fund's performance in different market conditions, its risk profile, and performance consistency. Fifth, Price pillar analysis covers the costs associated with a fund, especially, consideration of the fund's costs in light of its strategy.

\subsection{Hypotheses Development}

We expect that since the Analyst Ratings are intended to reflect long-term performance, they should be able to predict future performance. That is, funds with higher Analyst Ratings should demonstrate significantly better performance in the future. Haslem (2013) uses the new Analyst Ratings as one of the criteria for identifying stewardship mutual funds for individual investors and states that "Funds with Total (Pillar) Ratings of Gold, or perhaps Silver with a strong People (Pillar) Rating should be the focus." (pp. 24). We expect that funds with a higher People Pillar rating can strongly predict future performance. In addition, Morningstar states that the new Analyst Ratings reflect their belief about a fund's long-term prospects for risk-adjusted performance but they are not shortterm calls on a fund or an asset class (Kinnel, 2011). Based on the discussion of the Analyst Ratings in the preceding section, we expect that the contemporaneous relation between the new Analyst Ratings and the fund's performance should be weak. That is, the high Analyst Ratings should not be or should be weakly related to the current performance of the funds.

\section{DATA AND METHODOLOGY}

\subsection{Data and Sample}

Our main source of data is Morningstar Direct for fund performance measures and the Analyst Ratings. As of July 2013, we found that Analyst Ratings and Global Fund Reports were available for 1,159 individual mutual funds. Several funds offer different share classes, however, all share classes are assigned the same rating, thus, following Chen and Huang (2011), we select the first share class for each fund, listed in the Morningstar Direct database. Table 1 lists the descriptive statistics for our sample. All the variables are reported as annual values in December 2012. Sharpe Ratio and the Alpha are risk-adjusted returns. Morningstar recalculates Sharpe Ratio on a monthly basis and then annualizes it. It is a measure of a fund's historical risk-adjusted performance. We use it as a measure of contemporaneous risk-adjusted fund performance. Alpha is a measure of the difference between a fund's actual returns and its expected performance, given its level of risk as measured by beta. It measures three-year riskadjusted performance. We convert the Analyst Ratings and the Pillar Ratings to numerical grades for our analysis, where, Gold $=5$, Silver $=4$, Bronze $=3$, Neutral $=2$, Negative $=1$, and Positive $=3$, Neutral $=2$, Negative $=1$, respectively. Other control variables that we use are portfolio turnover ratio, total assets, age and the expense ratio. 
Table 1: Descriptive Statistics for the Variables Used

This table reports the descriptive statistics for the variables used in the analysis. The variables are obtained from the Morningstar Direct database and are retrieved for December 2012. Sharpe Ratio is the annualized monthly Sharpe Ratio, Alpha is the betaadjusted return over three years period, Turnover Ratio is the fund's portfolio turnover Ratio (\%), Total Assets is the total assets under management (in million \$), Age is the age of the fund (in years), Expense Ratio is the fund's expense ratio (\%), Analyst Rating is the overall Morningstar Analyst Rating, People Rating, Parent Rating, Process Rating, Performance Rating, Price Rating, are the ratings for the respective pillars.

\begin{tabular}{|l|c|c|c|c|c|c|}
\hline \multicolumn{1}{|c|}{ Variable } & $\mathbf{N}$ & Mean & Median & Std Dev & Minimum & Maximum \\
\hline Sharpe Ratio & 1,144 & 1.51 & 1.37 & 0.90 & -3.02 & 6.55 \\
\hline Alpha & 1,144 & 0.32 & 0.21 & 5.83 & -36.39 & 19.17 \\
\hline Turnover Ratio & 1,139 & 65.22 & 32.00 & 127.33 & 0 & 2,397 \\
\hline Total Assets & 1,155 & $1,695.54$ & $1,653.78$ & $50,786.61$ & 10.8 & $78,935.86$ \\
\hline Age & 1,157 & 12.91 & 11.05 & 9.87 & 0.01 & 83.56 \\
\hline Expense Ratio & 1,150 & 0.38 & 0.13 & 0.67 & 0 & 1.97 \\
\hline Analyst Rating & 1,157 & 3.16 & 3.00 & 1.13 & 1.00 & 5.00 \\
\hline People Rating & 1,153 & 2.68 & 3.00 & 0.54 & 1.00 & 3.00 \\
\hline Parent Rating & 1,153 & 2.41 & 2.00 & 0.59 & 1.00 & 3.00 \\
\hline Process Rating & 1,156 & 2.60 & 3.00 & 0.58 & 1.00 & 3.00 \\
\hline Performance Rating & 1,157 & 2.47 & 3.00 & 0.66 & 1.00 & 3.00 \\
\hline Price Rating & 1,157 & 2.45 & 3.00 & 0.75 & 1.00 & 3.00 \\
\hline
\end{tabular}

We also control for the stated fund objectives through dummy variables. Following Chen and Huang (2011), we merge the objective classifications into eight commonly known categories, namely, Balanced, Growth, Growth-Income, Asset Allocation, Specialty, International, Fixed Income, and Equity-Income. Table 2 presents the descriptive statistics for variables of interest, based on the eight fund objective categories.

Table 2: Descriptive Statistics for the Variables Used Under Different Fund Objective Categories

This table reports the descriptive statistics for the variables used in the analysis, based on eight fund objective categories. The variables are obtained from the Morningstar Direct database and are retrieved for December 2012. Sharpe Ratio is the annualized monthly Sharpe Ratio. Alpha is the beta-adjusted return over three years period. Analyst Rating is the overall Morningstar Analyst Rating, People Rating, Parent Rating, Process Rating, Performance Rating, Price Rating, are the ratings for the respective pillars.

\begin{tabular}{|l|c|c|c|c|c|c|c|c|c|}
\hline Fund Objective & $\mathbf{N}$ & $\begin{array}{c}\text { Sharpe } \\
\text { Ratio }\end{array}$ & Alpha & $\begin{array}{c}\text { Analyst } \\
\text { Rating }\end{array}$ & $\begin{array}{c}\text { People } \\
\text { Rating }\end{array}$ & $\begin{array}{c}\text { Parent } \\
\text { Rating }\end{array}$ & $\begin{array}{c}\text { Process } \\
\text { Rating }\end{array}$ & $\begin{array}{c}\text { Performance } \\
\text { Rating }\end{array}$ & $\begin{array}{c}\text { Price } \\
\text { Rating }\end{array}$ \\
\hline Balanced & 20 & 1.56 & 1.22 & 3.35 & 2.75 & 2.55 & 2.55 & 2.55 & 2.35 \\
\hline Growth & 371 & 1.13 & -1.69 & 3.19 & 2.70 & 2.41 & 2.65 & 2.56 & 2.27 \\
\hline Growth-Income & 136 & 1.36 & 0.12 & 3.38 & 2.57 & 2.44 & 2.59 & 2.43 & 2.73 \\
\hline Asset Allocation & 158 & 1.50 & 0.28 & 2.56 & 2.56 & 2.25 & 2.28 & 2.00 & 2.25 \\
\hline Specialty & 36 & 0.84 & -6.55 & 3.54 & 2.77 & 2.53 & 2.69 & 2.58 & 2.78 \\
\hline International & 188 & 1.33 & -1.00 & 3.33 & 2.74 & 2.53 & 2.72 & 2.57 & 2.41 \\
\hline Fixed Income & 217 & 2.56 & 6.11 & 3.16 & 2.73 & 2.36 & 2.59 & 2.55 & 2.66 \\
\hline Equity-Income & 31 & 1.34 & 0.01 & 3.32 & 2.74 & 2.47 & 2.74 & 2.77 & 2.71 \\
\hline
\end{tabular}

\subsection{Methodology}

As discussed above, the Analyst Ratings cover the five pillars that are analyzed independently; however, they do have some overlap, but vary substantially across funds. According to Chen and Huang (2011), Ordinary Least Squares (OLS) method is inappropriate for analysis in such a situation because OLS regression only estimates the conditional means, and therefore may fail to capture certain non-negligible relations between Morningstar Analyst Ratings and fund performance at the tails of fund performance distribution. In this case, quantile regression models may be more appropriate. Following Chen and Huang (2011), we use OLS, as well as, quantile regression models for our hypothesis testing, which are more appropriate for a heterogeneous mutual fund universe, with varying investment objectives and trading strategies. As mentioned in Section 1, since Analyst Ratings were introduced in November 2011, and Morningstar Direct does not report the rating date for each fund, we have made some assumptions to be able to carry out our analysis. First, we assume that all the funds in our sample were rated in December 2012, which enables us to be able to get all variables values for December 2012. We argue that since 
these ratings are intended to reflect the long-term prospects of a fund, there should not be frequent changes in the ratings for a fund, so a fund rated in late 2011 or in early 2013, should have the same rating in December 2012. Second, for testing whether the Analyst Ratings can predict future fund performance, we need more data, which is not available as of yet, because these are relatively newer ratings, with a long-term focus. We use the 3-year Alpha as a measure of future performance. We assume that the funds in our sample have the same rating in 2010 that they have in 2012 (again based on the assumption that these ratings do not change frequently). Morningstar states that the Analyst Ratings are unrelated to the Star Ratings, but still for this part of our analysis, we include only those funds that had the same Star Rating in 2010 and 2012. This reduces our sample size to 520 funds. We use the 3-year Alpha in 2012 to capture the funds' performance over the three years, 2010, 2011, and 2012. Our basic regression models are presented below:

$$
\begin{aligned}
& \text { PERF }=\propto_{0}+\sum_{i=1}^{7} \beta_{i} O B J_{i}+\beta_{8} A G E+\beta_{9} T R+\beta_{10} T A+\beta_{11} E R+\beta_{12} R A T I N G+\varepsilon \\
& P E R F=\propto_{0}+\sum_{i=1}^{7} \beta_{i} O B J_{i}+\beta_{8} A G E+\beta_{9} T R+\beta_{10} T A+\beta_{11} E R+\sum_{j=12}^{14} \beta_{j} P_{L L A R}+\varepsilon
\end{aligned}
$$

where, PERF is the measure of performance, either the 3-year Alpha, or the contemporaneous Sharpe Ratio. OBJ is the dummy variable for the fund objectives, AGE is the age of the fund in years, TR is the fund turnover ratio, TA is the total assets under management, ER is the expense ratio, RATING in equation (1) is the Analyst Rating. PILLAR in equation (2) is the rating for any of the pillars, namely, People, Parent, Process, or Price. Performance pillar is not included because the dependent variable is a measure of performance.

\section{RESULTS}

Table 3 presents the results for the OLS and quantile regression models where Alpha is the dependent variable and the Analyst Rating is the independent variable. The OLS coefficients indicate that the Analyst Rating is significantly positively related to the Alpha that is the measure of future risk-based performance. This shows that higher Analyst Ratings do predict better future performance. The OLS results also indicate a significant negative and positive relation between future performance and Specialty and Fixed Income funds, respectively. It is worth reiterating here that the Alpha is measured in 2012 and it measures the performance for years 2010, 2011, and 2012, and it is being assumed that the Analyst Ratings are the same in 2010 as in 2012. The other variables are measured for 2012. These results are easily reconciled given the weak economy and the low interest rates over these three years. OLS results also indicate that higher expense ratios result in poorer future performance. This is consistent with the literature (Gruber, 1996, and Carhart, 1997).

The remaining columns of Table 3 report the results for the quantile regression for the $10^{\text {th }}, 20^{\text {th }}, 30^{\text {th }}, 40^{\text {th }}$, $50^{\text {th }}, 60^{\text {th }}, 70^{\text {th }}, 80$ th, and the $90^{\text {th }}$ quantiles of the fund performance distribution. The main hypothesis of this paper is supported by these results. From Table 3, it is evident that Analyst Rating is significantly positively related to future performance along the entire distribution of the Alpha. However, the relation is slightly weaker in the right tail of the distribution, indicating that for better performing funds; higher Analyst Rating does not necessarily predict better performance in the future. The quantile regression results also indicate that for Specialty funds the significant negative coefficient in the OLS results are mainly driven by highly negative coefficients in the left tail of the distribution. However, it is interesting to see that toward the right tail $\left(70^{\text {th }}\right.$ and $80^{\text {th }}$ percentile); the relation is positive and significant. Positive significant coefficient on Fixed Income funds is consistent throughout and as stated above, it might be driven by the interest environment over the 3 years. For the most poorly performing funds $\left(10^{\text {th }}\right.$ percentile), higher expense ratios dampens future fund performance. 
Table 3: Results for Predictive Power of the Analyst Ratings

This table reports the coefficients for the OLS and quantile regressions where Alpha is the dependent variable. $\mathrm{N}=520$. Alpha is the beta-adjusted return over three years period, Turnover Ratio is the fund's portfolio turnover Ratio (\%), Total Assets is the total assets under management (in million \$), Age is the age of the fund (in years), Expense Ratio is the fund's expense ratio (\%), and Analyst Rating is the overall Morningstar Analyst Rating. D-Balanced, D-Growth, D-Growth-Income, D-Specialty, D-Fixed Income, D-International, and D-Allocation are dummy variables for fund objectives. $* * *, * *$, and $*$ indicate significance at the $1 \%, 5 \%$, and $10 \%$, respectively.

\begin{tabular}{|c|c|c|c|c|c|c|c|c|c|c|}
\hline \multirow[t]{2}{*}{ Variable } & \multirow[t]{2}{*}{ OLS } & \multicolumn{9}{|c|}{ Quantile } \\
\hline & & .1 & .2 & .3 & .4 & .5 & .6 & .7 & .8 & .9 \\
\hline Intercept & -1.58 & $-4.57 * * *$ & $-3.83 * * *$ & $-2.71 *$ & -2.08 & -0.97 & -0.83 & 0.34 & 0.51 & 0.91 \\
\hline D-Balanced & 0.66 & 1.79 & 0.44 & 0.72 & 1.54 & 1.01 & 0.63 & 0.13 & 0.15 & -1.55 \\
\hline D-Growth & -1.38 & -1.52 & $-2.06^{* * *}$ & -1.82 & -1.66 & -1.71 & $-1.67 *$ & $-1.26^{*}$ & 0.05 & -0.88 \\
\hline D-Growth-Income & -0.27 & 0.63 & -0.10 & -0.10 & -0.15 & -0.09 & -0.48 & -0.61 & -0.43 & -0.80 \\
\hline D-Specialty & $-6.14 * * *$ & $-24.40 * * *$ & $-17.46^{* * *}$ & $-15.55 * * *$ & -9.40 & 2.13 & 2.43 & $3.47 * *$ & $3.6 * *$ & 3.90 \\
\hline D-Fixed Income & $6.34 * * *$ & $4.68 * * *$ & $4.47 * * *$ & $5.63 * * *$ & $5.97 * * *$ & $6.18 * * *$ & $6.83 * * *$ & $6.91 * * *$ & 7.70 *** & $8.06^{* * * *}$ \\
\hline D-International & -0.93 & -1.72 & $-2.23 * *$ & $-2.30 * *$ & $-2.05^{*}$ & -1.18 & -1.09 & -0.58 & 0.97 & 0.99 \\
\hline D-Allocation & 0.59 & 1.94 & 0.10 & 0.85 & 0.60 & 0.35 & 0.37 & -0.09 & 0.09 & -0.21 \\
\hline Age & 0.12 & -0.01 & 0.03 & 0.02 & 0.02 & $0.02 *$ & 0.02 & 0.02 & $0.04 *$ & $0.08 * *$ \\
\hline Turnover $\mathrm{X} 10^{3}$ & 0.01 & -0.00 & -0.80 & -1.70 & -0.30 & -0.10 & -0.20 & 1.80 & 0.20 & 3.60 \\
\hline Total Assets & -0.28 & 0.00 & 0.00 & -0.00 & -0.00 & -0.00 & -0.00 & -0.00 & -0.00 & -0.00 \\
\hline Expense Ratio & $-0.42 *$ & $-0.78 * * *$ & -0.24 & -0.25 & -0.31 & -0.37 & -0.14 & $-0.40 *$ & -0.38 & 0.23 \\
\hline Analyst Rating & $0.71 * * *$ & $0.69 * * *$ & $0.70 * * *$ & $0.60 * * *$ & $0.56^{* * * *}$ & $0.45 * * *$ & $0.53^{* * * *}$ & $0.41^{* *}$ & $0.38 * * *$ & $0.39 * *$ \\
\hline
\end{tabular}

Table 4: Results for Predictive Power of the Pillar Ratings

This table reports the coefficients for the OLS and quantile regressions where Alpha is the dependent variable. N = 520. Alpha is the beta-adjusted return over three years period, Turnover Ratio is the fund's portfolio turnover Ratio (\%), Total Assets is the total assets under management (in million \$), Age is the age of the fund (in years), Expense Ratio is the fund's expense ratio (\%), and Analyst Rating is the overall Morningstar Analyst Rating. D-Balanced, D-Growth, D-Growth-Income, D-Specialty, D-Fixed Income, D-International, and D-Allocation are dummy variables for fund objectives. People Rating, Parent Rating, and Process Rating are the ratings for the respective pillars. $* * *, * *$, and $*$ indicate significance at the $1 \%, 5 \%$, and $10 \%$, respectively.

\begin{tabular}{|c|c|c|c|c|c|c|c|c|c|c|}
\hline \multirow[t]{2}{*}{ Variable } & \multirow[t]{2}{*}{ OLS } & \multicolumn{9}{|c|}{ Quantile } \\
\hline & & .1 & .2 & .3 & .4 & .5 & .6 & .7 & .8 & .9 \\
\hline Intercept & $-4.22 * *$ & $-8.01 * * *$ & $-8.08 * * *$ & $-5.52 * * *$ & $-4.82 * * *$ & $-4.02 * *$ & $-2.68 * *$ & -0.97 & -0.72 & -1.37 \\
\hline D-Balanced & 0.50 & 1.33 & 1.07 & 1.64 & 1.60 & 1.01 & 1.55 & 0.15 & -0.18 & -0.43 \\
\hline D-Growth & -1.35 & $-1.25^{*}$ & $-1.89 * *$ & $-1.70^{* * *}$ & -1.61 & -1.71 & -0.83 & -0.87 & -0.03 & 0.64 \\
\hline D-Growth-Income & 0.04 & 1.10 & 0.83 & 0.58 & 0.62 & 0.86 & -0.24 & -0.60 & -0.23 & 0.33 \\
\hline D-Specialty & $-6.08 * * *$ & $-25.60 * * *$ & $-17.01 * * *$ & $-14.89 * * *$ & $-9.26^{*}$ & 2.84 & 2.61 & $3.75^{* *}$ & $3.86 * *$ & $5.64 * *$ \\
\hline D-Fixed Income & $6.33 * * *$ & $3.89 * * *$ & $4.87 * * *$ & $5.82 * * *$ & $6.09 * * *$ & $7.34 * * *$ & $6.89^{* * * *}$ & $7.21 * * *$ & 7.59 *** & $9.36^{* * * *}$ \\
\hline D-International & -0.93 & $-2.50 * *$ & $-2.19 * *$ & $-2.20 * *$ & $-1.80^{*}$ & -0.76 & -1.02 & -0.36 & 1.09 & 2.13 \\
\hline D-Allocation & 0.21 & 1.43 & $1.41 *$ & 0.82 & 0.74 & 0.88 & 0.21 & 0.15 & 0.09 & 0.91 \\
\hline Age & 0.01 & -0.02 & 0.02 & 0.01 & 0.02 & 0.02 & 0.02 & $0.03 *$ & $0.03 *$ & $0.06^{* *}$ \\
\hline Turnover $\times 10^{3}$ & 0.44 & 0.50 & -0.40 & -1.30 & 0.50 & -0.00 & -0.80 & 2.10 & 0.70 & 4.00 \\
\hline Total Assets & -0.18 & $0.00^{*}$ & $0.00^{*}$ & 0.00 & 0.00 & -0.00 & -0.00 & -0.00 & -0.00 & -0.00 \\
\hline Expense Ratio & -0.41 & -0.33 & -0.17 & -0.15 & -0.21 & -0.28 & -0.30 & -0.35 & -0.32 & 0.10 \\
\hline People Rating & $0.23 * *$ & 0.59 & $1.01 * *$ & $0.82 *$ & $0.89 * *$ & $0.74 * *$ & $0.83 *$ & 0.09 & 0.28 & -0.12 \\
\hline Process Rating & 0.15 & 0.76 & $0.71 * *$ & 0.49 & 0.34 & 0.13 & 0.05 & 0.02 & 0.08 & 0.23 \\
\hline Parent Rating & 0.45 & $0.88^{* * *}$ & $0.60 * *$ & 0.38 & 0.37 & 0.53 & 0.52 & $0.90 * * *$ & 0.28 & $0.91^{*}$ \\
\hline
\end{tabular}


In Table 4, we examine the individual pillars of the Analyst Rating. The OLS results in Table 4 are consistent with the OLS results in Table 3. Specialty and Fixed Income funds are significantly negatively and positively related to the Alpha, respectively. Expense ratio becomes insignificant. However, the OLS results support our hypothesis that funds with higher People Ratings will perform better in the future. The quantile results show that for the poorly performing funds (left tail), being an International fund results in poorer future performance. In these results, of interest is the variable People Rating. It appears that for funds in the middle of the performance distribution $\left(20^{\text {th }}\right.$ to $60^{\text {th }}$ percentile), a higher People Rating predicts a better future performance. This is consistent with our hypothesis. The results also indicate that having a higher Parent Rating is better for funds in both the tails of the performance distribution.

Next, we examine whether the Analyst Ratings are related to contemporaneous fund performance. We use OLS regression models for this purpose and the results are presented in Table 5. The dependent variable is the Sharpe Ratio and the results show that Analyst Ratings are significantly positively related to contemporaneous fund performance. This indicates that even though Analyst Ratings are not based on short-term performance measures, our results indicate that they are related. The People and Process Ratings are also individually significantly related to the Sharpe Ratio.

Table 5: OLS Results for Contemporaneous Fund Performance

This table reports the results for the OLS regression. Sharpe Ratio is the dependent variable. The variables are obtained from the Morningstar Direct database and are retrieved for December 2012. Sharpe Ratio is the annualized monthly Sharpe Ratio, Alpha is the beta-adjusted return over three years period, Turnover Ratio is the fund's portfolio turnover Ratio (\%), Total Assets is the total assets under management (in million \$), Age is the age of the fund (in years), Expense Ratio is the fund's expense ratio (\%), Analyst Rating is the overall Morningstar Analyst Rating, People Rating, Parent Rating, Process Rating, and Price Rating are the ratings for the respective pillars. $* * *, * *$, and $*$ indicate significance at the $1 \%, 5 \%$, and $10 \%$, respectively.

\begin{tabular}{|l|c|c|c|}
\hline \multicolumn{1}{|c|}{ Variable } & & & \\
\hline Intercept & $0.95^{* * *}$ & $0.60^{* * *}$ & $0.46^{* *}$ \\
\hline D-Balanced & 0.19 & 0.21 & 0.23 \\
\hline D-Growth & -0.17 & -0.17 & -0.16 \\
\hline D-Growth-Income & 0.03 & 0.07 & 0.07 \\
\hline D-Specialty & $-0.49^{* * *}$ & $-0.46^{* * *}$ & $-0.46^{* * *}$ \\
\hline D-Fixed Income & $1.22^{* * *}$ & $1.25^{* * *}$ & $1.26^{* * *}$ \\
\hline D-International & 0.01 & 0.01 & 0.02 \\
\hline D-Allocation & $0.27^{*}$ & $0.28^{*}$ & $0.28^{*}$ \\
\hline Age & 0.003 & 0.003 & 0.003 \\
\hline Turnover X 10 & $0.37 * *$ & $0.30^{*}$ & $0.29^{*}$ \\
\hline Total Assets & 0.34 & 0.52 & 0.52 \\
\hline Expense Ratio & $-0.10^{*}$ & $-0.02^{* *}$ & \\
\hline Analyst Rating & $0.10^{* * *}$ & & $0.14^{* * *}$ \\
\hline People & & $0.10^{*}$ & $0.14 * * *$ \\
\hline Process & & 0.003 & $0.11^{* *}$ \\
\hline Parent & & & 0.008 \\
\hline Price & & 1126 & 0.04 \\
\hline N & $36.63 \%$ & $37.98 \%$ & 1127 \\
\hline Adj. R & & & $37.83 \%$ \\
\hline
\end{tabular}

\section{CONCLUSIONS}

Morningstar introduced the Analyst Ratings in November 2011 to reflect the long-term risk-adjusted performance of mutual funds. The overall ratings are a synthesis of five fundamentals of a fund, namely, People, Parent, Process, Performance, and Price. In this paper, we examine whether the Analyst Ratings can predict future performance by using quantile regression models, to account for the variability in fund objectives and strategies. Our results indicate that if we assume that the funds were rated in 2010, those ratings are significantly positively related to future performance of the funds, measured by the 3-year Alpha in 2012, that captures performance in 2010, 2011, and 2012. We also find that higher People Ratings are significantly positively related to future performance. Our results also indicate that even though Morningstar insists that these Ratings are unrelated to contemporaneous 
performance of the funds, we find a significant relation between the Analyst Ratings and contemporaneous fund performance.

We note that the results may be sensitive to our underlying assumptions; nevertheless, these results are important for individual and institutional investors who depend on the Morningstar ratings to make their investment decisions. The results support the argument that the new Analyst ratings do have predictive power for future performance and investors should choose funds with a high Analyst Rating, and possibly a high People Rating as well.

\section{AUTHOR INFORMATION}

Dr. Rashiqa Kamal is an Assistant Professor in the Department of Finance and Business Law at the University of Wisconsin-Whitewater. She can be contacted at: Department of Finance and Business Law, College of Business and Economics, University of Wisconsin-Whitewater, 800 W. Main St., Whitewater, WI 53190. Her research has been published in Journal of Corporate Finance and Managerial Finance. She can be contacted at: phone 262-472-5446. E-mail: kamalr@uww.edu

\section{REFERENCES}

1. Blake, Christopher R., and Morey, Matthew R. (2000). Morningstar Ratings and Mutual Fund Performance. Journal of Financial and Quantitative Analysis. 35(3) 451-483.

2. Carhart, Mark M. (1997). On persistence in mutual fund performance. Journal of Finance. 52(1) 57-82.

3. Chen, Carl R., and Huang, Ying (2011). Mutual Fund Governance and Performance: A Quantile regression Analysis of Morningstar's Stewardship Grade. Corporate Governance: An International Review. 19(4) 311-333.

4. Del Gerico D., and Tkac, P.A. (2008). Star Power: The Effect of Morningstar Ratings on Mutual Fund Flow. Journal of Financial and Quantitative Analysis. 43(4) 907-936.

5. Gruber, Martin J. (1996). Another puzzle: The growth in actively managed mutual funds. Journal of Finance. 51(3) 783-810.

6. Haslem, John A. (2013). Identifying Stewardship Mutual Funds for Individual Investors. The Journal of Investing. 22(1), 104-111.

7. Kinnel, R. (2011). The Pillars of Our New Analyst Ratings. Retrieved from: http://www.morningstar.com/advisor/t/48668520/the-pillars-of-our-new-analyst-ratings.htm

8. Morey, Matthew R. (2005). The Kiss of Death: A 5-Star Morningstar Mutual Fund Rating? Journal of Investment Management. 3(2) 41-52.

9. Morningstar Factsheet (2013). Retrieved from: http://corporate.morningstar.com/us/documents/MarketingFactSheets/AboutMorningstarFactsheet.pdf

10. Wellman, Jay W., and Zhou, Jian (2007). Corporate Governance and Mutual Fund Performance: A First Look at the Morningstar Stewardship Grades. Retrieved from: http://papers.ssrn.com/sol3/papers.cfm?abstract id=714303 